\title{
The Summoning of Everynumber
}

\author{
Peter R. Mercer $\odot$
}

\section{The Summoning of Everynumber}
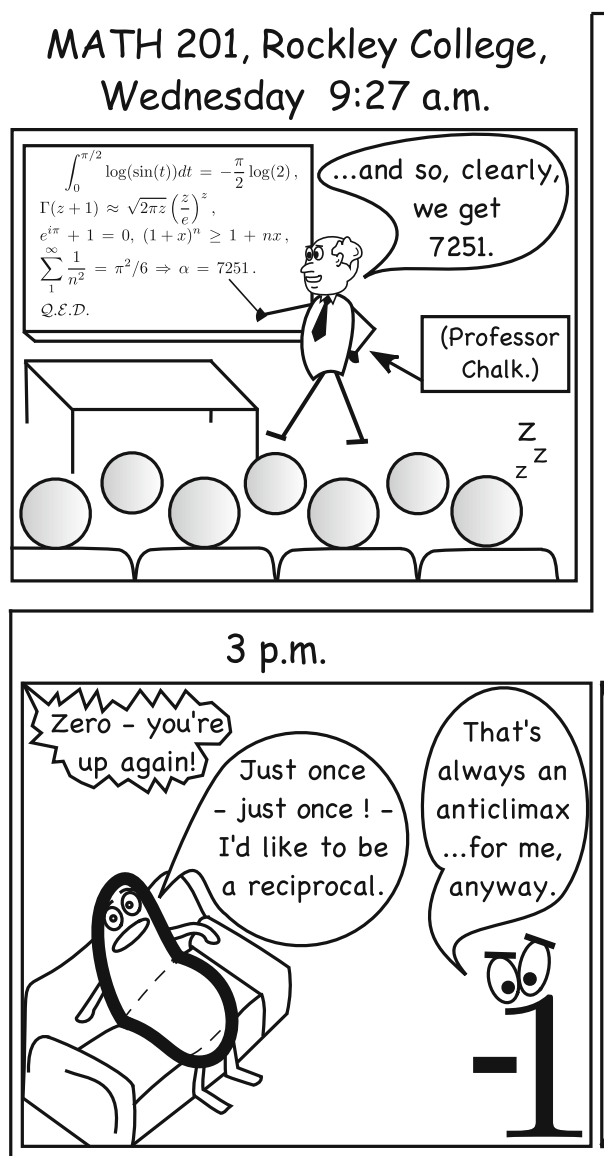

Plato's World of Forms - Department of Numbers.

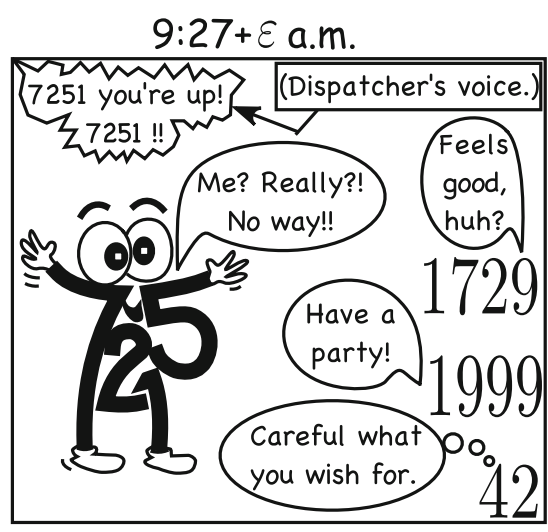

6 p.m.



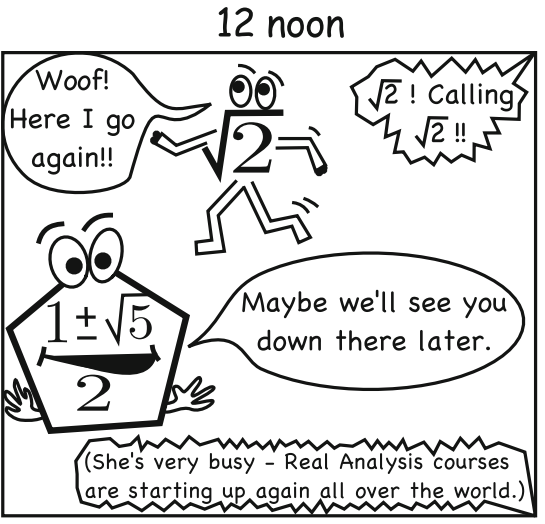

And later that evening...

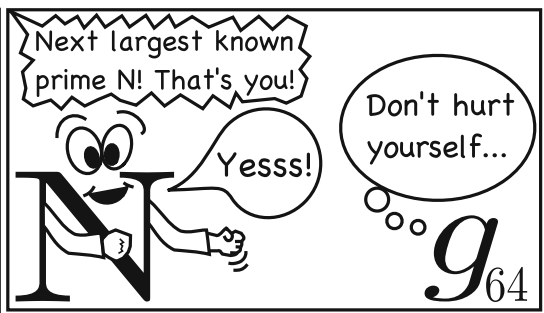

The next-next-largest known prime readies herself. Not far away are the twin primes, Fibonacci primes, perfect numbers, zeros of the Zeta function...

Publisher's Note Springer Nature remains neutral with regard to jurisdictional claims in published maps and institutional affiliations. 